\title{
Changes of Hairy vetch Biomass by Different Seeding Methods and Rice Growth and Soil Physicochemical Properties by Its Incorporation in Paddy
}

\author{
Weon-Tai Jeon*, Jin-Hee Ryu, Ki-Yeong Seong, Min-Tae Kim, Hang-Won Kang, \\ Jae-Eun Lee, Chan-Sik Jung, and Wook-Han Kim \\ National Institute of Crop Science, RDA, Suwon 441-857, Republic of Korea
}

(Received: July 1 2013, Accepted: August 8 2013)

Hairy vetch can fix nitrogen from the atmosphere as a leguminous cover crop. This research was caried out to determine optimum seeding method of hairy vetch and application effect in paddy. Field experiment was conducted at Sinheung series (fine loamy, mixed, nonacid, mesic family of Fluvaquentic Endoaquepts) from Sep. 2011 to Oct. 2012 at the National Institute of Crop Science (NICS), RDA, Suwon, Gyeonggi province, Korea. Hairy vetch used in the study was 'Cheongpyungbora', developed by National Institute of Crop Science. Seeding methods of hairy vetch consisted of Broadcasting Before Rice Harvesting (BBRH), Partial Tillage Seeding (PTS), Minimum Tillage Seeding (MTS), No Tillage Seeding (NTS), and Drill Seeding (DS). Both MTS and NTS showed the highest biomass among the seeding methods. The rice yield of MTS and NTS significantly increased compared to conventional fertilization (CF). Also soil properties including organic matter and bulk density were improved by incorporation of hairy vetch. Therefore, we suggested that MTS and NTS could be used to produce hairy vetch and rice in paddy.

Key words: Hairy vetch, Seeding method, Rice, Yield, Paddy

Biomass and nitrogen production of hairy vetch by different seeding methods in paddy.

\begin{tabular}{|c|c|c|c|}
\hline Seeding method & Fresh weight & Dry weight & $\mathrm{N}$ production \\
\hline & \multicolumn{3}{|c|}{ - kg 10a ${ }^{-1}$} \\
\hline $\mathrm{BBRH}^{\dagger}$ & $1,480 \mathrm{~b}$ & $314 b$ & $9.8 \mathrm{a}$ \\
\hline PTS $^{\ddagger}$ & $1,857 \mathrm{ab}$ & $329 a$ & $9.6 \mathrm{a}$ \\
\hline $\mathrm{MTS}^{\S}$ & $2,349 a$ & $355 \mathrm{a}$ & $10.5 \mathrm{a}$ \\
\hline NTS & $2,065 \mathrm{a}$ & $328 \mathrm{a}$ & $10.0 \mathrm{a}$ \\
\hline $\mathrm{DS}^{\phi}$ & $1,555 \mathrm{~b}$ & $291 \mathrm{c}$ & $9.1 \mathrm{a}$ \\
\hline
\end{tabular}

${ }^{\dagger}$ BBRH: Broadcasting Before Rice Harvesting, ${ }^{\dagger}$ PTS: Partial Tillage Seeding, ${ }^{\S}$ MTS: Minimum Tillage Seeding, "NTS: No Tillage Seeding ${ }^{\natural}$ DS: Drill Seeding. 


\section{Introduction}

녹비작물은 화학비료 대체, 토양 물리성· 화학성 - 생물상 개선 및 경관 보전 효과 등 다양한 효과를 가지고 있다 (Azam, 1990; Hartwig and Ammon, 2002; Clark, 2007: Jeon et al., 2008; Jeon et al., 2011). 우리나라에서 녹비 의 재배에 대한 문헌상의 기록은 세종 때 편찬된 농사직설 에 녹두를 녹비로 이용했다는 기록이 있으며 그 후 조선후 기에는 녹비의 종류도 다양해졌다고 한다 (Kim et al., 2012). 일제강점기인 1930년대 자운영 $100,000 \mathrm{ha}$, 헤어리베치 50,000 ha 정도까지 재배되었다고 한다 (Lee, 1983). 최근 친환경 농업에 대한 생산자와 소비자의 관심으로 녹비작물 재배 면적이 2010년 144,000 ha까지 증가 (FACT, 2011) 하 였으나 자운영의 알파파바구니 발생 증가 및 종자 수출국인 중국의 작황 저조 등으로 종자 수입이 급감하여 재배면적이 감소하고 있는 실정이다. 녹비작물 중 두과 녹비작물인 헤 어리베치는 화학비료 대체 효과가 뛰어나 우리나라에 많이 보급되고 있는 중이다. 그러나 2012년 우리나라 녹비작물의 재배면적은 다소 감소하였으나 $98,098 \mathrm{ha}$ 로 이 중 헤어리 베치의 재배면적은 $42,700 \mathrm{ha}$ 로 $43.5 \%$ 를 차지하고 있다 (MAF, 2012). 그러므로 헤어리베치의 보급 확대를 위하여 안정적 재배기술 개발이 시급하다. 지금 우리나라에 재배되 고 있는 헤어리베치는 벼입모중파종이 대부분을 차지하고 있다. 벼입모중파종은 생력적인 재배방법이기는 하지만 볏 짚으로 피복되기 때문에 한해 등에 기상변화에 취약하다 (Kim et al., 2002). 그 후 다소 월동 안전성이 높은 부분경 운 파종법을 개발 (Jeon et al., 2011) 하였으나 최근 이상기 상 등 기후변화에 대응하기 위한 다양한 파종방법 개발에 대 한 연구는 미미한 실정이다. 따라서 본 연구는 녹비작물로써 효과가 높은 헤어리베치의 재배안정성과 벼에 대한 이용 효 과를 높이고자 다양한 파종방법별 생초중, 건물중 및 질소 생산성에 대한 평가 및 논토양에 환원 시 벼 생육 및 수량, 토양 이화학성 변화의 기초 자료를 얻고자 수행하였다.

\section{Materials and Methods}

본시험은 경기도 수원시에 소재한 농촌진흥청 국립식량 과학원 벼 연구포장 (신흥통)에서 2011년 9월부터 2012년 10 월까지 수행하였다. 시험에 사용된 헤어리베치의 품종은 국립식량과학원에 육성한 청풍보라를 사용하였다. 파종방 법은 벼입모중파종, 부분경운파종, 최소경운파종, 무경운파 종, 세조파이었고 벼 입모중은 2011년 9월 25일에 파종하였 고 그 외 파종은 벼 수확후 10 월 13 일에 파종하였다. 모든 처리의 헤어리베치 파종량은 10a 당 $6 \mathrm{~kg}$ 을 파종하였다. 벼 수확 전 입모중 파종은 손으로 파종하였고, 그 외 파종은 벼 수확 후 파종을 하였다. 부분경운 파종 (Jeon et al., 2008)
은 트랙터 부착 파종기, 최소경운 파종은 트랙터 부착 파종 기 (원판식, 장자동화), 무경운 파종은 파종기 (복토직파기, 금강기건)를 이용하였고 세조파는 로타리 경운 후 세조파기 (L65, LG, Korea)를 이용하여 파종하였다.

녹비작물 재배, 조사 및 분석 녹비작물 biomass 조사 는 2012년 5 월 19에 $1 \mathrm{~m}^{2}(1 \mathrm{~m} \times 1 \mathrm{~m})$ 의 면적을 기준으로 하 여 녹비작물을 채취하여 생초중을 측정한 후 비닐하우스에 서 충분히 풍건 후 $60^{\circ} \mathrm{C}$ 에서 24 시간 충분히 건조시켜 건물 중을 측정하여 기록하였다. 녹비작물의 투입은 2012년 5월 20 일에 로타리 경운으로 환원하였다. 식물체의 질소와 탄소 는 CNS2000 (Leco, USA)을 이용하여 분석하였고 그 외 분 석은 토양 및 식물체 분석은 농촌진흥청 (NIAST, 2000) 방 법에 준하였다.

벼 재배 및 생육, 수량조사 벼 품종은 윤작체계상 숙 기가 다소 빠른 조생종인 운광벼를 이용하였다. 파종은 플 라스틱 산파육묘상자 $(30 \times 60 \times 3 \mathrm{~cm})$ 에 마른 종자 기준 $130 \mathrm{~g}$ 을 소독, 침종, 최아 후 파종하였다. 유묘는 25 일간 육 묘하여 2012년은 6월 4일에 기계 이앙하였다. 벼 재배 시 관행 시비구는 $10 \mathrm{a}$ 당 질소 - 인산 - 칼리를 각각 9.0 $4.5-5.7 \mathrm{~kg}$ 을 시용하였고 질소는 50 (기비) -20 (분얼비) - 30\% (수비)로 분시하였고, 인산은 전량 기비, 칼리는 기 비로 $70 \%$, 수비로 $30 \%$ 분시하였다. 벼 재배 중 생육과 수량 및 수량구성요소는 농업과학기술 연구조사분석기준 (RDA, 2003)에 준하여 조사를 수행하였다. 벼 재배 중 생육조사는 분얼기(이앙 후 10 일)와 유수형성기(이앙 후 42 일) 출수기 (이앙 후 63일)에 초장, 경수, 엽색도를 조사하였다.

토양 분석 시험 전 토양분석을 위하여 녹비작물 재배 전에 표토 $0 \sim 10 \mathrm{~cm}$, 심토 $10 \sim 20 \mathrm{~cm}$ 깊이에서 3 반복으로 채취하였다. 채취한 시료는 음건하여 $2 \mathrm{~mm}$ 체를 통과된 것 을 화학성 분석에 사용하였다. 토양화학성 분석은 농업과학 기술원 토양 및 식물체 분석법 (NIAST, 2000)을 적용하여 $\mathrm{pH}$ 는 토양과 증류수의 비율을 1:5로 하여 초자전극법(720P, iSTEK, USA)으로 측정하였고, 유기물은 원소분석기 CNS2000 (LECO, USA)를 이용하여 탄소를 분석하여 탄소함량에 계 수 1.724 를 곱하여 산출하였고 질소분석에도 CNS2000을 이 용하였다. 유효인산은 Lancaster 법, 양이온은 ICP (GBC SDS-270, Australia)를 사용하여 분석하였다. 벼 재배기간 중인 분얼기와 유수형성기에 토양 암모니아태 질소를 분석 하였다. 분석은 Inject flower meter인 FIAstar5000 (FOSS Sweden)로 분석하였다.

통계분석 방법 통계분석은 SAS 9.2. 버전을 이용하였 다. 벼 수량 및 수량구성요소 등은 $5 \%$ 유의수준에서 Duncan's 
multiple range test를 수행하였다.

\section{Results and Discussion}

녹비작물 헤어리베치를 환원하기 전에 파종방법별 biomass 및 질소 생산성을 조사하였다 (Table 1). 생초중은 벼입모중 파종에 비하여 최소경운 및 무경운파종에서 높았고 건물중 은 벼입모중파종에 비하여 부분경운, 최소경운 및 무경운파 종이 높았다. 그러나 질소 생산성은 파종방법간 유의적 차 이가 없는 경향을 보였다. Biomass 생산 측면에서 보면 답 리작의 헤어리베치의 생산은 농가에서 많이 행해지고 있는 벼입모중파종보다 벼 수확 후 파종을 하는 부분경운파종이 안전성 높은 것으로 연구되어 있다 (Jeon et al., 2008; Jeon et al., 2011). 이 결과에 따르면 토양 속에 파종되는 헤어리베치 종자는 월동의 안정이 더 높은 것으로 보고하였 다. 본 시험에서는 벼입모중파종이 다른 파종법보다 biomass 생산이 다소 떨어지는 것은 이러한 것에 원인이 있는 것으 로 생각되었다.

헤어리베치 환원 벼 주요 생육시기별 생육조사를 수행하 였다 (Table 2). 조사 시기는 벼 분얼초기인 이앙 후 10 일,

Table 1. Biomass and nitrogen production of hairy vetch by different seeding methods in paddy.

\begin{tabular}{lccc}
\hline \hline Seeding method & Fresh weight & Dry weight & N production \\
\hline & ----------- & $k g ~ 10 a^{-1}$ & ----------- \\
BBRH $^{\dagger}$ & $1,480 \mathrm{~b}$ & $314 \mathrm{~b}$ & $9.8 \mathrm{a}$ \\
$\mathrm{PTS}^{\ddagger}$ & $1,857 \mathrm{ab}$ & $329 \mathrm{a}$ & $9.6 \mathrm{a}$ \\
$\mathrm{MTS}^{\S}$ & $2,349 \mathrm{a}$ & $355 \mathrm{a}$ & $10.5 \mathrm{a}$ \\
$\mathrm{NTS}^{\natural}$ & $2,065 \mathrm{a}$ & $328 \mathrm{a}$ & $10.0 \mathrm{a}$ \\
$\mathrm{DS}^{\oint}$ & $1,555 \mathrm{~b}$ & $291 \mathrm{c}$ & $9.1 \mathrm{a}$ \\
\hline
\end{tabular}

'BBRH: Broadcasting Before Rice Harvesting, ${ }^{\ddagger}$ PTS: Partial Tillage Seeding, ${ }^{\S}$ MTS: Minimum Tillage Seeding, "NTS: No Tillage Seeding ${ }^{\dagger}$ DS: Drill Seeding.
유수형성기인 이앙 후 42 일, 출수기인 이앙 후 63 일에 초장 및 경수를 조사하였다. 분얼초기인 이앙 후 10 일에는 녹비 환원구가 화학비료구에 비하여 초장과 경수가 적은 경향이 었으나 이앙 후 42 일경에는 화학비료구에 비하여 헤어리베 치 환원구가 초장과 경수가 많았다. 출수기인 이앙 후 63 일 에는 경수는 이앙 후 42 일과 유사한 경향이었으나 초장은 관행시비와 차이가 없었다. 이앙 후 42 일과 63 일에는 엽색 도 (SPAD)를 조사하였는데 이앙 후 42 일에는 초장과 경수 와 유사한 경향으로 헤어리베치 환원구가 유의적으로 높았 으나 출수기인 이앙 후 63 일에 유의적 차이가 없었다. 이는 유수형성기 조사 후 관행시비구에는 이삭거름 (수비)을 시 용하였기 때문인 것으로 판단되었다.

논토양에서의 환원상태이기 때문에 질소의 이용형태는 암모니아태 질소로 벼에 이용이 된다. 생육조사 (Table 2)와 동일한 시기에 암모니아태 질소를 분석하였다 (Table 3). 관 행시비구는 분석 후 분얼비와 이삭거름을 시용하였다. 이앙 후 10 일에는 관행시비구에 비하여 모든 헤어리베치 훤원구 에서 암모니아태 질소의 함량이 높았고 특히 최소 및 무경 운구에 높았고 벼 입모중파종구에서 낮았다. 벼입모중파종 구에서 낮은 것은 볏짚이 훤원된 것에 원인이 있는 것으로 사료되었다. 환원 후 시기가 경함에 따라서 처리간 차이가 적었으나 최소경운과 무경운구에서 높은 것은 무경운의 효 과로 추정되었다 (Kim et al., 2011).

헤어리베치 환원후 조사한 벼의 수량 및 수량구성요소는 Table 4와 같다. 수량구성요소 중 수당립수, 등숙비율 및 천 립중은 다소 헤어리베치 환원구에서 낮은 경향을 보였으나 유의적 차이는 없었다. 그러나 벼 수량구성요소 중한 기여 도 높은 이삭수는 헤어리베치 환원구에서 높은 경향이었다. 헤어리베치 같은 녹비작물은 추비의 시용이 없기 때문에 초 기 경수의 확보로 충분한 수수 (이삭수)의 확보가 중요하다. Table 2와 3 에 나타난 것과 같이 생육 중에 헤어리베치 환 원구가 암모니아태 질소의 생성이 높고 경수가 충분하여 관 행시비보다 많은 이삭수를 확보할 수 있었다. 이러한 이유

Table 2. Height, tiller number, and leaf color of rice by different seeding methods in paddy.

\begin{tabular}{|c|c|c|c|c|c|c|c|c|}
\hline \multirow{2}{*}{$\begin{array}{l}\text { Seeding } \\
\text { method }\end{array}$} & \multicolumn{2}{|c|}{ 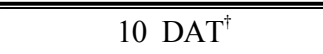 } & \multicolumn{3}{|c|}{42 DAT } & \multicolumn{3}{|c|}{63 DAT } \\
\hline & $\begin{array}{l}\text { Plant height } \\
\text { (cm) }\end{array}$ & $\begin{array}{c}\text { Tiller } \\
\text { (no./hill) }\end{array}$ & $\begin{array}{l}\text { Plant height } \\
\text { (cm) }\end{array}$ & $\begin{array}{c}\text { Tiller } \\
\text { (no./hill) }\end{array}$ & $\begin{array}{c}\text { Leaf color } \\
\text { (SPAD) }\end{array}$ & $\begin{array}{l}\text { Plant height } \\
\text { (cm) }\end{array}$ & $\begin{array}{c}\text { Tiller } \\
\text { (no./hill) }\end{array}$ & $\begin{array}{c}\text { Leaf color } \\
\text { (SPAD) }\end{array}$ \\
\hline$\overline{\mathrm{BBRH}^{\ddagger}}$ & $20.1 \mathrm{a}$ & $5.7 \mathrm{a}$ & $72.5 \mathrm{a}$ & $21.3 \mathrm{a}$ & $40.6 \mathrm{a}$ & $92.5 \mathrm{a}$ & $15.2 \mathrm{a}$ & $36.9 a$ \\
\hline $\mathrm{PTS}^{\S}$ & $18.8 \mathrm{a}$ & $4.9 \mathrm{a}$ & $67.3 \mathrm{a}$ & $20.4 \mathrm{a}$ & $39.7 \mathrm{a}$ & $86.9 \mathrm{a}$ & $14.3 \mathrm{a}$ & $37.2 \mathrm{a}$ \\
\hline MTS & $19.0 \mathrm{a}$ & $5.3 \mathrm{a}$ & $69.8 \mathrm{a}$ & $23.0 \mathrm{a}$ & $38.9 \mathrm{a}$ & $88.7 \mathrm{a}$ & $15.2 \mathrm{a}$ & $36.1 \mathrm{a}$ \\
\hline $\mathrm{NTS}^{\phi}$ & $19.7 \mathrm{a}$ & $5.0 \mathrm{a}$ & $67.9 \mathrm{a}$ & $22.2 \mathrm{a}$ & $39.5 \mathrm{a}$ & $90.7 \mathrm{a}$ & $14.9 \mathrm{a}$ & $39.4 \mathrm{a}$ \\
\hline $\mathrm{DS}^{\jmath}$ & $17.7 \mathrm{a}$ & $5.8 \mathrm{a}$ & $67.7 \mathrm{a}$ & $21.6 \mathrm{a}$ & $40.8 \mathrm{a}$ & $88.9 \mathrm{a}$ & $13.7 \mathrm{a}$ & $38.3 \mathrm{a}$ \\
\hline $\mathrm{CF}^{\|}$ & $24.2 \mathrm{a}$ & $6.2 \mathrm{a}$ & $62.0 \mathrm{ab}$ & $16.0 \mathrm{~b}$ & $33.9 \mathrm{~b}$ & $90.6 \mathrm{a}$ & $10.8 b$ & $36.4 \mathrm{a}$ \\
\hline
\end{tabular}

†DAT: Days After Transplanting, ${ }^{\ddagger}$ BBRH: Broadcasting Before Rice Harvesting, ${ }^{8}$ PTS: Partial Tillage Seeding, "MTS: Minimum Tillage Seeding, ${ }^{\dagger}$ NTS: No Tillage Seeding ${ }^{j}$ DS: Drill Seeding, ${ }^{j /}$ CF: Conventional Fertilization. 
Table 3. Changes in soil $\mathrm{NH}_{4}-\mathrm{N}$ concentration at $0-10 \mathrm{~cm}$ soil depthafter hairy vetch incorporation.

\begin{tabular}{|c|c|c|c|}
\hline \multirow{2}{*}{ Seeding method } & $10 \mathrm{DAT}^{\dagger}$ & 42 DAT & 63 DAT \\
\hline & \multicolumn{3}{|c|}{ 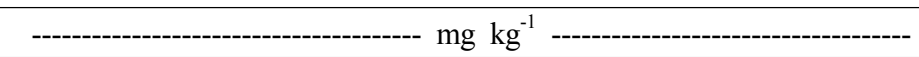 } \\
\hline$\overline{\mathrm{BBRH}^{*}}$ & $2.50 \mathrm{c}$ & $9.88 \mathrm{a}$ & $4.91 \mathrm{~b}$ \\
\hline $\mathrm{PTS}^{\S}$ & $8.64 b$ & $14.1 \mathrm{a}$ & $6.39 \mathrm{ab}$ \\
\hline MTS $^{*}$ & $9.66 \mathrm{~b}$ & $10.6 \mathrm{a}$ & $8.60 \mathrm{a}$ \\
\hline $\mathrm{NTS}^{\phi}$ & $16.5 \mathrm{a}$ & $11.2 \mathrm{a}$ & $8.15 \mathrm{a}$ \\
\hline $\mathrm{DS}^{\jmath}$ & $4.01 \mathrm{~b}$ & $8.76 a$ & $4.90 \mathrm{~b}$ \\
\hline $\mathrm{CF}^{\| \tilde{J}}$ & $5.86 \mathrm{~b}$ & $5.49 \mathrm{~b}$ & $3.45 b$ \\
\hline
\end{tabular}

$\mp, \ddagger, \S, \Phi, \oint, f, \Omega$ see table 2 .

Table 4. Effects of incorporation of hairy vetch on rice yield and its components in response to different seeding methods.

\begin{tabular}{|c|c|c|c|c|c|}
\hline Seeding method & Panicle & Spikelets & Ripened grain & 1,000 grain weight & Rice yield \\
\hline & no. hill $^{-1}$ & no. panicle $^{-1}$ & $\%$ & Brown rice, $g$ & $\mathrm{~kg} 10 \mathrm{a}^{-1}$ \\
\hline $\mathrm{BBRH}^{+}$ & $16.6 \mathrm{a}$ & $92.5 \mathrm{a}$ & $73.7 b$ & $20.8 \mathrm{a}$ & $498.1 \mathrm{c}$ \\
\hline $\mathrm{PTS}^{\S}$ & $15.8 \mathrm{a}$ & $94.7 \mathrm{a}$ & 78.9ab & $22.0 \mathrm{a}$ & $506.7 \mathrm{~b}$ \\
\hline MTS & $16.2 \mathrm{a}$ & $90.4 \mathrm{a}$ & $75.1 \mathrm{ab}$ & $21.6 \mathrm{a}$ & $526.9 \mathrm{a}$ \\
\hline NTS $^{\phi}$ & $16.3 \mathrm{a}$ & $85.8 \mathrm{a}$ & $68.7 b$ & $21.1 \mathrm{a}$ & $523.3 \mathrm{a}$ \\
\hline $\mathrm{DS}^{j}$ & $16.5 \mathrm{a}$ & $87.4 \mathrm{a}$ & $69.2 b$ & $20.6 \mathrm{a}$ & $518.6 \mathrm{ab}$ \\
\hline $\mathrm{CF}^{\|}$ & $15.2 \mathrm{ab}$ & $93.4 \mathrm{a}$ & $82.0 \mathrm{a}$ & $23.0 \mathrm{a}$ & $498.1 \mathrm{c}$ \\
\hline
\end{tabular}

\$, $, q, \oint, \uparrow, \|$ see table 2 .

Table 5. Effects of seeding methods of green manure crops on soil physical properties.

\begin{tabular}{|c|c|c|c|}
\hline Seeding method & Soil depth & Bulk density & Soil porosity \\
\hline & $\mathrm{cm}$ & $\mathrm{Mg} \mathrm{m}^{-3}$ & $\%$ \\
\hline $\mathrm{BBRH}^{+}$ & $0-10$ & 1.19 & 55.2 \\
\hline $\mathrm{PTS}^{\S}$ & & 1.13 & 55.5 \\
\hline MTS & & 1.15 & 56.8 \\
\hline $\mathrm{NTS}^{\oint}$ & & 1.12 & 57.8 \\
\hline $\mathrm{DS}^{\jmath}$ & & 1.24 & 53.3 \\
\hline $\mathrm{CF}^{\|}$ & & 1.20 & 54.6 \\
\hline $\mathrm{BBRH}^{*}$ & $10-20$ & 1.29 & 51.5 \\
\hline $\mathrm{PTS}^{\S}$ & & 1.30 & 51.1 \\
\hline MTS & & 1.32 & 50.1 \\
\hline $\mathrm{NTS}^{\phi}$ & & 1.31 & 50.6 \\
\hline $\mathrm{DS}^{\jmath}$ & & 1.27 & 52.0 \\
\hline $\mathrm{CF}^{\| f}$ & & 1.29 & 51.4 \\
\hline
\end{tabular}

\$, $, q, £, f, \|$ see table 2 .

에서 관행시비구보다 높은 수량을 보인 것으로 생각된다. 특히 최소경운과 무경운파종구에서 관행시비 $(498.1 \mathrm{~kg} / 10 \mathrm{a})$ 에 비하여 $5 \sim 5.8 \%$ 증수되었다.

벼 수확 후 토양의 물리성을 조사한 결과는 Table 5 와 같 다. 녹비작물을 환원하면 토양의 물리성이 개선되는 것으로 보고되어 있다 (Jeon et al., 2008). 본 시험의 결과도 헤어
리베치 환원구에서 토양의 용적밀도가 낮아지고 공극률이 높아지는 경향을 보였다. 토양물리성은 표토가 심토보다 더 많이 개선됨을 알 수 있다. 이는 벼 재배 시 유의 해야 될 사항으로 표토의 물리성만 개선되면 오히려 태풍 등이 내습 시 도복이 유발될 수 있다. 따라서 녹비작물 환원 시 심토까 지 물리성이 개선 할 수 있는 연구가 추가적으로 필요할 것 
Table 6. Effects of seeding methods of green manure crops on soil chemical properties.

\begin{tabular}{|c|c|c|c|c|c|c|c|}
\hline \multirow{2}{*}{ Seeding method } & \multirow{2}{*}{ Soil depth } & \multirow{2}{*}{$\mathrm{pH}$} & \multirow{2}{*}{$\mathrm{OM}$} & \multirow{2}{*}{ Av. $\mathrm{P}_{2} \mathrm{O}_{5}$} & \multicolumn{3}{|c|}{ Ex. cations } \\
\hline & & & & & $\mathrm{K}$ & $\mathrm{Ca}$ & $\mathrm{Mg}$ \\
\hline & $\mathrm{cm}$ & $1: 5$ & $\%$ & $m g \mathrm{~kg}^{-1}$ & \multicolumn{3}{|c|}{ - } \\
\hline $\mathrm{BBRH}^{\ddagger}$ & $0-10$ & 5.60 & 2.80 & 37 & 0.18 & 4.10 & 0.97 \\
\hline PTS $^{\S}$ & & 5.39 & 2.82 & 50 & 0.12 & 3.70 & 0.82 \\
\hline MTS $^{\pi}$ & & 5.57 & 2.77 & 40 & 0.17 & 3.82 & 0.86 \\
\hline $\mathrm{NTS}^{\phi}$ & & 5.75 & 2.82 & 48 & 0.21 & 4.27 & 0.98 \\
\hline $\mathrm{DS}^{\jmath}$ & & 5.64 & 2.85 & 49 & 0.14 & 3.95 & 0.87 \\
\hline $\mathrm{CF}^{\mathscr{I}}$ & & 5.58 & 2.63 & 87 & 0.14 & 4.31 & 0.92 \\
\hline $\mathrm{BBRH}^{\dagger}$ & $10-20$ & 6.01 & 2.96 & 39 & 0.22 & 4.71 & 1.21 \\
\hline $\mathrm{PTS}^{\S}$ & & 6.44 & 2.84 & 57 & 0.15 & 5.37 & 1.33 \\
\hline MTS $^{\pi}$ & & 6.28 & 2.80 & 46 & 0.18 & 4.67 & 1.29 \\
\hline $\mathrm{NTS}^{\phi}$ & & 5.98 & 2.88 & 50 & 0.24 & 4.33 & 1.10 \\
\hline $\mathrm{DS}^{\jmath}$ & & 6.37 & 2.95 & 63 & 0.15 & 4.90 & 1.31 \\
\hline $\mathrm{CF}^{\Omega}$ & & 5.87 & 2.57 & 69 & 0.17 & 4.92 & 1.19 \\
\hline
\end{tabular}

$\$, \S, \uparrow, \uparrow, \|$ see table 2 .

으로 사료되었다. 또한 헤어리베치 환원 시 벼의 내도복 증 진을 위하여 품종 선발 및 물관리 기술도 개발이 필요할 것 으로 생각되었다.

헤어리베치를 환원하여 벼 재배 후 토양 화학성을 조사 한 것이 Table 6이다. 토양 $\mathrm{pH}$ 는 일정한 경향은 없었으나 헤어리베치 환원구에서 약간 증가하는 경향을 보였다. 유기 물은 헤어리베치 환원구에서 증가하였고 유효인산은 감소 하였는데 토양의 지속적이 비옥도 유지를 위해서는 녹비 시 용 시 인산함량 증가 기술 개발이 필요할 것으로 생각되었 다. 양이온들은 일정한 경향이 없었는데 이는 관개수의 영 향을 많이 받는 것으로 추정되었다.

\section{Conclusion}

본시험은 답리작에서 녹비작물 헤어리베치의 안전적 재 배를 위하여 파종방법별 생산성과 벼 이용 시 생육, 토양변 화 특성의 기초 자료를 얻고자 경기도 수원시에 소재한 농 촌진흥청 국립식량과학원 벼 연구포장 (신흥통)에서 2011년 9월부터 2012년 10월까지 수행하였다. 시험에 사용된 헤어 리베치의 품종은 국립식량과학원에 육성한 청풍보라를 사 용하였다. 파종방법은 벼입모중파종, 부분경운파종, 최소경 운파종, 무경운파종, 세조파이었고 벼 입모중은 2011년 9월 25 일에 파종하였고 그 외 파종은 벼 수확 후 10 월 13 일에 파 종하였다. 2012년 5월 19일에 biomass을 조사한 결과 최소 경운과 무경운파종에서 생초중과 건물중이 높았고 질소생 산성도 $10 \mathrm{a}$ 당 02 0.7 kg 높았다. 파종방법별 헤어리베치 이용 쌀수량도 헤어리베치의 biomass와 동일한 경향으로
최소경운파종과 무경운 파종구에서 관행 $(498.1 \mathrm{~kg} / 10 \mathrm{a})$ 에 비하여 $5 \sim 5.8 \%$ 증수되었다. 벼 재배 후 토양의 물리성은 무경운 파종구에서 용적밀도는 적어지고 공극률이 증가하 는 경향이었고 토양화학성은 관행 재배구에 비하여 녹비 처 리구에서 유기물이 약간 증가하는 경향으로 추후 무경운 파 종과 최소경운 파종에 대한 면밀한 검토가 필요할 것으로 생각되었다.

\section{References}

Azam, F. 1990. Comparative effects of organic and inorganic nitrogen sources applied to a flooded soil on rice yield and availability of N. Plant Soils. 125:255-262.

Clark, A. 2007. Managing cover crops profitably (third edition). Sustainable agriculture network. MD, USA.

FACT (Foundation of Agri. Tech. Commercialization \& Transfer). 2011. The Guidebook of Agro-green Technologies. Sammi. Suwon. pp. 193-213.

Hartwig, N.L. and H.U. Ammon. 2002. Cover crop and living mulches. Weed Sci. 50:688-699.

Jeon W.T., M.T. Kim, K.Y. Seong, and I.S. Oh. 2008. Changes of soil properties and temperature by green manure under rice-based cropping system. Korean J Crop Sci 53:413-416.

Jeon, W.T., B.S. Choi, Abd EL-Azeem SAM, and Y.S. Ok. 2011. Effect of different seeding methods on green manure biomass, soil properties and rice yield in rice based cropping systems. African J Biotechnol 10:2024-2031.

Jeon, W.T., K.Y. Seong, M.T. Kim, I.S. Oh, B.S. Choi, and U.G. Kang. 2011. Effect of Biomass and N Production by Cultivation Methods of Leguminous and Gramineae Green 
Manures on Rice Growth in Central Regions of Korea. Korean J. Soil Sci. Fert. 44(5): 853-858.

Kim, C.G., J.H. Seo, H.S. Cho, S.H. Cho, and S.J. Kim. 2002. Effect of hairy vetch as green manure on rice cultivation. Korean J. Soil Sci. 35(3):169-174.

Kim, M.K, Y.H. Lee, T.H. Kang, and H.D. Yun. 2011. Influence of Chinese Milkvetch (Astragalus sinicus L.) with No-tillage on Soil Biotic Factors and Rice Yield. J. Korean Soc. Appl. Biol. Chem. 54(6): 899-909.

Kim, M.T., W.T. Jeon, H.S. Cho, S.J. Kim, Y.H. Lee, M.C. Seo, and H.W. Kang. 2012. Crop for crop cultivation. RDA
Interrobang: 86.

Lee, H. J. 1983, The history of Korea agricultural technology. V. Production technology of forage and green manure crops. Jungminsa. Suwon Korea pp. 433-459.

MAF (Ministry of Agriculture and Forestry, Republic of Korea). 2012. MAF, Korea.

NIAST (National institute of Agricultural Science and Technology). 2000. Methods of analysis of soil and plant, NIAST, Suwon, Korea.

RDA. 2003. Standard methods for agricultural experiments. Rural Development Administration, Suwon, Korea. 